\title{
The Multi-Subject Cooperation Mechanism of Home Care for the Disabled Elderly in Beijing: A Qualitative Research
}

\section{Ruyi Zhang}

Capital Medical University

\section{Zhiying Zhang}

Capital Medical University

Yingchun Peng ( $\nabla_{\text {pycjql@ccmu.edu.cn ) }}$

Capital Medical University

\section{Shaoqi Zhai}

Capital Medical University

Jiaojiao Zhou

Fengtai District Xiluoyuan Community Health Service Center, Beijing

Jingjing Chen

Huairou District Liulimiao Community Health Service Center, Beijing

\section{Research Article}

Keywords: disability, elderly, multiple subjects, home care, qualitative research

Posted Date: February 2nd, 2022

DOI: https://doi.org/10.21203/rs.3.rs-1199316/v1

License: (9) (1) This work is licensed under a Creative Commons Attribution 4.0 International License. Read Full License 


\section{Abstract}

Background: Currently, population aging has been an obstacle and the spotlight for all countries. Compared with developed countries, problems caused by China's aging population are more prominent. Beijing, as a typical example, is characterized by advanced age and high disability rate, making this capital city scramble to take control of this severe problem. Moreover, influenced by traditional culture, disabled elderly people prefer to stay at home rather than go to nursing home. Home care for the disabled elderly is facing pushback from the whole society, such as lack of professional medical care, social support and humanistic care, and the care resources provided by a single department cannot meet the needs of the disabled elderly. Therefore, in order to meet the diverse needs of the disabled elderly and improve their quality of life, it is urgent to strengthen joint efforts of the government, society, family members, etc., and establish a collaborative mechanism to provide home-based care resources more efficiently and accurately.

Objective: Based on the demands of the disabled elderly and their families, this study aims to explore the current status of homse care service supply process that multiple subjects involved in, and to give some advice on how to build a multi-subject coordination mechanism of home care for the disabled elderly in Beijing.

Methods: A total of 118 disabled elderly people and their primary caregivers were selected from four districts of Beijing by using multi-stage stratified proportional sampling method. A one-to-one and semi-structured in-depth qualitative interview study was conducted in the study to find out the health status of the disabled elderly, the relationship between the disabled elderly and their primary caregivers, and utilization of elderly care resources, etc. Thematic framework analysis was utilized, the researchers summarized six aspects to express. All the methods were carried out in accordance with relevant guidelines and regulations.

Results: Multiple subjects (such as the society, government, family doctors, family members and the elderly themselves) play a large role in the home care. But there is a lot of space need to improve, including a lack of high levels of interaction. In internal factors, the qualitative research results showed that the average age of 118 disabled elderly is $81.38 \pm 9.82$ years; $72.9 \%$ (86) is severe disability; $89.0 \%$ (105)is plagued by chronic diseases; the average duration of disability is $5.63 \pm 5.25$ years; disease is the principal cause of disability $(95,80.51 \%)$; the psychological problems of the disabled elderly are prominent; and the disabled elderly are not aware of the relevant pension policies; most of disabled elderly have $2.56 \pm 1.44$ children, but the primary caregiver is their own partner $(42,35.6 \%)$, and there is an uneven sharing of responsibilities for the disabled elderly among their offspring in the process of home care. In external factors terms, the demands of the disabled elderly in home are not yet met; the disability subsidy is low and not in full coverage. As a result, establishing multi-subject coordination mechanism of home care for the disabled elderly has further to run.

Conclusions: In a nutshell, the disabled elderly and their families in Beijing grapple with heavy financial burden, physical and psychological problems; however, the current home care provided by multiple subjects is insufficient and is short of a multi-subject coordination mechanism. Therefore, more home care services should be considered and better cooperation among multiple subjects should be set up for the disabled elderly and their caregivers. Specifically, family members act as the guardians of the disabled elderly, they should take more responsibility for the daily lives' care, like creating a warm and family-friendly atmosphere and giving more time to stay together and so forth; family doctors should provide professional technical guidance and assist other subjects to participate in the process of home care; the government should establish relevant pension policies, and unveil more incentive policies to encourage more family doctors and social groups to create a concerted effort; social groups as a supplementary role to provide care services at need and promote the development of the service industry. Multi-subject coordination mechanism represents different subjects bearing respective responsibility for the disabled elderly, reducing the financial burden is the top priority to solve. Keeping consistency in the goals of multiple subjects, expanding the participation and health 
care service and enhancing cooperation is essential, the cooperation among multiple subjects exert each other's advantages on home care leading to providing home care resources more efficiently and accurately. Multi-subject coordination mechanism working well and closely ensures a positive future for the disabled elderly.

\section{Introduction}

With the deepening of the aging of society, there are a growing number of elderly, which has become a social problem cannot be ignored. According to statistics, Beijing is one of the most aging cities in China. The total permanent population of 60 years old and above in 2020 has reached 4.299 million, accounting for $19.6 \%$. The 65 years old and above population in 2020 is 2.912 million, comes at 13.3\% [1]. The aging population in Beijing presents the distribution characteristics of a high degree of aging in the urban areas and relatively low in the suburbs, and a trend of the rapid growth of advanced age. Moreover, due to the social structure of population aging, it is inevitable that care for the elderly have brought great challenges to multiple subjects. . In 2020, there were 130,000 disabled elderly people in Beijing who had obtained the Civil Affairs Department's disability certification and received relevant subsidies. Nowadays, the main types of care for the disabled elderly are classified as home care, institutional care, and community care. Compared with institutional care, $85 \%$ of seniors are inclined to home care, but more than $60 \%$ of elderly indicate that the family environment has difficulty adapting to changes of their physical conditions[2]. Family caregivers are short of professional nursing knowledge and care tools, and they are unable to employ medical treatment for the disabled elderly in emergency.

In order to deeply understand what difficulties that disabled elderly are being confronted with and what support is required in the process of home care, this study has selected disabled elderly and their families with different characteristics from urban areas, mountainous areas, and plains of Beijing for in-depth interviews. The approach is designed to establish a home care service system and enhance the quality of disabled elderly care services.

\section{Research Objects And Methods}

\subsection{Research objects}

\subsubsection{Selection of research objects}

Taking the level of economic development and the linear distance from Tiananmen Square of each district into account, this study has selected 15 community health service centers (CHS centers) in 4 districts of Beijing as research sites, 2 from urban areas and 2 suburbs respectively. (namely Xicheng District, Fengtai District, Daxing District, and Huairou District).Then, 3-4 community health service centers are selected from each district. Xicheng and Fengtai District are the core functional areas in Beijing, in terms of the 2020 Beijing Regional Statistics Yearbook[3], Xicheng's per capita disposable income is the highest among the six urban areas, at 88,291 yuan; while Fengtai has the lowest per capita disposable income, at 65,215 yuan. Daxing District is a representative of the plains areas in the suburbs of Beijing. In 2020, the per capita disposable income of Daxing is 47,432 yuan, which is the $9^{\text {th }}$ place among the 16 districts in Beijing. Huairou District is a representative of mountainous areas in the suburbs of Beijing, its per capita disposable income is 40,067 yuan, ranking $12^{\text {th }}$ among all the districts in Beijing.

Now, the CHS centers in the whole communities of Beijing all have family doctor teams. Policies detail the tasks to respond to care for disabled elderly, family doctors should provide contracted services and conduct health management for the group. On the basis of the situation of the disabled elderly (age $\geq 60$ ) who have contracted by the family doctor team in each community health service center, 118 cases of disabled elderly are selected according to the ratio of $3 \%$ from the health management files by adopting multi-stage stratified proportional sampling method, the 
118 disabled elderly and their family members/caregivers are interviewed personally and in-depth during the same period.

\subsubsection{Inclusion criteria and exclusion criteria}

Inclusion criteria: $₫$ Disabled elderly assessed by the Beijing Municipal Civil Affairs Department; $₫$ Able to express their personal wishes independently and clearly; खKnow the research purpose of the subject and participate voluntarily. $\otimes$ Family members who have provided long-term care (more than six months) are accompanied to participate, and the caregivers also have obtained informed consent.

Exclusion criteria: $\triangle T$ The disabled elderly or their caregivers have a mental disorder; $\triangle T$ The disabled elderly are unwilling to participate or not able to cooperate with the research; $₫$ Caregivers are unwilling to accompany and take an active part in.

\subsection{Research methods: Qualitative research}

Under the national and Beijing's relevant policies of home care for the disabled elderly, the research team has considered the humanistic environment, regional characteristics and the actual situation of the contracted services in Beijing and compiled an interview outline after extensive review of relevant literature and repeated discussion by panel experts.

The content of the interview contains the basic information of disabled elderly, their health status, the status quo of geriatric care, the demands of the disabled elderly and their families, the degree of utilization of home care resources, and specific advice for the disabled elderly of home care. One-to-one, semi-structured in-depth personal interviews are conducted in this study. All the interviewers have been trained by a unified standard in advance to avoid inductive questions and reduce research bias. Before the interview, the interviewer gives a detailed introduction of the study purpose, methods, content and confidentiality principles to the interviewees and obtains informed consent[4]. In order to reduce traffic inconvenience of the disabled elderly, the interviews are engaged in their homes, to ensure the accuracy and completeness of the information, and the entire processes recorded with the consent of the interviewees. The content of the recordings is transcribed in detail by members of the research team within 24 hours after the interview completed to ensure the authenticity of the survey data. The interviewees are anonymized, and the names of the disabled elderly are coded with $\mathrm{N} 1 \mathrm{~N} 118$.

\subsection{Statistical Methods: Thematic framework}

The content analysis method is used to conduct qualitative analysis of the interview data, and the data are classified and analyzed by identifying themes, data labeling, and extracting core information[5]. The content of the interview is summarized as follows:

For the disabled elderly and their families $\rrbracket$

What is the relationship between the primary caregiver and the disabled elderly? What reasons does the elderly choose this caregiver?

What difficulties do families of the disabled elderly have in caring for the elderly in their daily lives?

\Are the disabled elderly and their families willing to accept voluntary services?

Page $4 / 28$ 
For family doctors $₫$

What services do the family doctor provide for the disabled elderly?

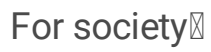

What is the status quo of care services supply provided by neighborhood committees, volunteers, neighbors, and care institutions for the disabled elderly?

For multiple subjects $₫$

What do the disabled elderly and their families think the government, family doctors, society, family members and the elderly themselves should do to improve the current situation of home care?

\section{Results}

2.1 Basic information 
Table 1 Demographic characteristics of the disabled elderly

\begin{tabular}{|c|c|}
\hline Items & Number of surveys (\%) \\
\hline \multicolumn{2}{|l|}{ Urban-rural distribution } \\
\hline Rural area & $55 \rrbracket 46.6 \rrbracket$ \\
\hline Urban area & $63 \rrbracket 53.4 \rrbracket$ \\
\hline \multicolumn{2}{|l|}{ Gender } \\
\hline Male & $59 \llbracket 50.0 \rrbracket$ \\
\hline Female & $59 \llbracket 50.0 \rrbracket$ \\
\hline \multicolumn{2}{|l|}{ Age } \\
\hline $60<=$ age $<70$ & 18ه15.3》 \\
\hline $70<=$ age $<80$ & $26 \rrbracket 22.0 \rrbracket$ \\
\hline $80<=$ age $<90$ & 44『37.3邓 \\
\hline $90<=$ age $<100$ & $30 \rrbracket 25.4 \rrbracket$ \\
\hline \multicolumn{2}{|l|}{ Education } \\
\hline Elementary school or below & 49₫41.5》 \\
\hline Secondary school & $44 \llbracket 37.3 \rrbracket$ \\
\hline Junior college & 18ه15.3》 \\
\hline University or above & $7 \rrbracket 5.9 \rrbracket$ \\
\hline \multicolumn{2}{|l|}{ Disability level } \\
\hline Mild disability & $12 \bigotimes 10.2 \rrbracket$ \\
\hline Moderate disability & $20 \bigotimes 16.9 \rrbracket$ \\
\hline Severe disability & 86ه72.9》 \\
\hline \multicolumn{2}{|l|}{ Duration of disability } \\
\hline$<=1$ year & $24 \bowtie 20.3 \rrbracket$ \\
\hline 1 year $<$ Length of disability <=10year & 79ه66.9ه \\
\hline 10year< Length of disability & $15 \rrbracket 12.7 \rrbracket$ \\
\hline \multicolumn{2}{|l|}{ Morbidity of chronic diseases } \\
\hline Not have & $13 \bigotimes 11.0 \rrbracket$ \\
\hline Have & $105 \llbracket 89.0 \rrbracket$ \\
\hline \multicolumn{2}{|l|}{ Basic medical insurance } \\
\hline Medical insurance for urban and rural residents & $76 \rrbracket 64.4 \rrbracket$ \\
\hline Urban employee medical insurance & $36 \rrbracket 30.5 \rrbracket$ \\
\hline Low-budget medical assistance & 1区0.8》 \\
\hline
\end{tabular}




\section{Total}

$118(100)$

\subsubsection{Demographic characteristics of the disabled elderly}

The demographic characteristics of the 118 disabled elderly people interviewed is shown in the table 1: खUrban-rural distribution: 63 disabled elderly people are from cities and the rest (55) are from rural areas. $₫$ Gender: There is a balanced distribution between men and women, each accounting for $50 \%$. Aage: Among the participants, the youngest is 61 years old and the oldest is 99 years old, with an average age of $81.38 \pm 9.82$ years old. The seniors over 80 years old have exceeded half of the interviewed. 区Education level: $41.5 \%$ of the interviewees have a primary school education or below. $₫$ Disability level: The severely disabled elderly are the majority, with 86 people, accounting for $72.9 \%$. खDuration of disability: The minimum disability period is within 1 year, and the maximum period of disability is 30 years. The average duration of disability is $5.63 \pm 5.25$ years. Most elderly who have owned duration of disability are within the range from 1 year to 10 years. $\otimes$ Morbidity of chronic diseases: Only 13 disabled elderly people interviewed are in good health condition, 75 (63.6\%) are subjected to hypertension, and 42 (35.6\%) are type 2 diabetes. खBasic medical insurance: 76 people (64.4\%) use urban and rural residents' medical insurance, 36 (30.5\%) get urban employees' medical insurance, 5 (4.2\%) enjoy public medical care and 1 (0.8\%) low-budget medical assistance.

2.1.2 The main reasons resulting in the disability

\begin{tabular}{|c|c|}
\hline The main reasons & Number of surveys $₫ \% \bigotimes$ \\
\hline Old age & $11 \otimes 9.3 \rrbracket$ \\
\hline Cerebral infarction & $36 \rrbracket 30.5 \rrbracket$ \\
\hline Myocardial infarction & $7 \rrbracket 5.9 \rrbracket$ \\
\hline Malignant tumor & $9 \otimes 7.6 \rrbracket$ \\
\hline Other diseases & $43 \bowtie 36.4 \rrbracket$ \\
\hline External force damage & $12 \rrbracket 10.2 \rrbracket$ \\
\hline Total & 118ه100.0区 \\
\hline
\end{tabular}

As shown in the table 2, the main reasons resulting in the disability of the disabled elderly are diseases, such as hypertension, diabetes, rheumatoid arthritis, lumbar spine stenosis and other diseases prevalent in the elderly. Cerebral infarction is the main causes of disability among the elderly, followed by malignant tumors and myocardial infarction. Due to advanced age and external force injuries, the number of the disabled elderly are accounted for $11(9.3 \%)$ and $12(10.2 \%)$, respectively.

\subsubsection{The primary caregiver of the disabled elderly in home}

Among the 118 elderly people interviewed, 4 elderly have no kids, 22 of them have only 1 child, and most elderly have 2 children, accounting for $33.9 \%$. The number of children owned by the disabled elderly is $2.56 \pm 1.44$. As indicated in the table 3 below, the primary caregivers of disabled elderly mostly are their partner, with 42 (35.6\%). 
Table 3 The primary caregiver of the disabled elderly in home

\begin{tabular}{|c|c|}
\hline Primary caregiver & Number of surveys $₫ \% \bigotimes$ \\
\hline Wife or husband & $42 \varangle 35.6 \rrbracket$ \\
\hline Son & $18 \otimes 15.3 \rrbracket$ \\
\hline Daughter & $12 \varangle 10.2 \rrbracket$ \\
\hline Daughter-in-law & $13 \otimes 11.0 \otimes$ \\
\hline Son-in-law & $1 \otimes 0.8 \otimes$ \\
\hline Nanny & $21 \otimes 17.8 \rrbracket$ \\
\hline Other relatives & $5 \rrbracket 4.2 \rrbracket$ \\
\hline No fixed caregiver (children's shift) & $6 \rrbracket 5.1 \rrbracket$ \\
\hline Total & 118ه100.0》 \\
\hline
\end{tabular}

2.2 The division of home care responsibilities

2.2.1 The relationship with the primary caregiver and the reasons why the disabled elderly choose this primary caregiver

It is found that most of primary caregivers are their wives or husbands (42/118). In the interview, the elderly indicated that the main reasons for choosing their partners to take care are as follows: $₫$ Their children are busy at work and only their partners can take care of them (31/118). As the disabled elderly N16 mentioned, "My son and daughter have not retired yet, they are busy reconciling work and family responsibilities, they also need to take care of their grandchildren and deal with their own housework." $\nabla \mid \mathrm{lt}$ is more comfortable to live with their partners $(11 / 118)$. The disabled elderly N5 mentioned, "My wife is in good health and she is able to attend me. Her care makes me feel more comfortable and attentive."

The interview results also demonstrates that most of disable elderly choose to live in their son's home and they are looked after by their sons and daughters-in-law, or a nanny(37/118), while only a few elderly choose to live in their daughter's home. The reasons are as follows: $\otimes$ They think their sons should be held responsibility (7/118). N42, a disabled elderly person, mentioned, "I think it is natural in China for my son to take responsibility for me when I am old." $\otimes$ They think their married daughter belongs to other family and they don't want to bother them. The disabled elderly N23 mentioned, "In our country, the daughter who married is like the water poured out. I don't want to trouble my daughter anymore because she has her own family."

\subsubsection{The Division of Responsibilities among the Family Members}

With regard to the division of care responsibilities among family members, the disabled elderly interviewed generally stated that there is no clear division of responsibilities (97/118). The disabled elderly N71 said, "Family is a place where minds come in contact with one another. If these minds love one another, the home will be harmonious and united. So there is no clear division of responsibilities in my family for who are responsible to take care of me. Someone who has more time, he/she may need to put more effort into looking after my daily life. Someone who has better financial condition, he/she would pay more money on me." 
Only a few families have a clear division of responsibilities for taking care of disabled elderly (21/118), they share the responsibilities by using the following strategies: $₫$ Allocate economic responsibilities and care responsibilities (15/118). N51 mentioned that "I have many children, but they all have their own business to cope with. The way to solve the problem of care responsibilities is that the second daughter and the youngest daughter pay money monthly for me and the eldest daughter who is mainly responsible for caring."

QThe disabled elderly take turns to live in their children's home (6/118). The N91 mentioned, "I have 4 children, and I live in each child's home for 3 months in a year. Every child can observe his/her filial piety."

2.2.3 Using the same caregiver steadily for a long time or changing regularly

(1) Using the same caregiver steadily for a long time (100/118). The main reasons are as follows:

QThe caregiver who take a long term care for the disabled elderly is more familiar with the health status of the elderly, which is beneficial to the health of the elderly (21/118). For example, the disabled elderly N85 said, "I think it is good for one person to take care of me for a long time, because regularly change the caregiver is not good for my health."

هThe emotional demands(19/118). As the disabled elderly N50 mentioned, "I also hope not to change the person who attends on me for a long time, because I will feel very close to someone who has lived with me for a long time."

$\nabla T$ The disabled elderly need to adapt the caregiver's living habits (10/118). For example, the N20 stated, "Everyone has their own living habits, it is difficult for me to adapt to other's lifestyle. If I change the caregiver, I still need a long period of adaptation."

QFor some families, there is no suitable person to replace, and only one person can undertake such task(60/118). For example, the daughter-in-law of the disabled elderly N43 mentioned, "The strong hope of my family is to maintain the status quo. The mother-in-law only knows me now. If others touch her, she will get angry." The N46 mentioned, "I just have a son and there are no other kids around to provide support."

(2) Changing the caregivers regularly(18/118). The main reasons are as follows:

$\nabla T h e$ sole caregiver is under a lot of pressure (7/118). As mentioned by N64, a disabled elderly, "I think it's better to rotate regularly, because there are too much pressure for my children to take care of me."

$\bigotimes$ The offspring share the care responsibilities equally, which is relatively fair (9/118). For instance, the disabled elderly N36 mentioned, "There is no dispute over the care responsibilities of multiple-child family to share the responsibilities equally, and it is more beneficial for children to look after me."

\Nanny has highly mobility (2/118). For example, the disabled elderly N67 said that "The nanny needs to be replaced frequently because she has to go home. She also has her own family and I cannot force her to stay my house for a long time."

2.3 The difficulties that the primary caregiver may face in the process of home care (answered mainly by the family members of the disabled elderly, the disabled elderly supplemented on the site)

\ Caring for the elderly requires a lot of effort, and the caregiver's personal health is generally too weak to take on the heavy pressure (92/118). For example, the disabled elderly N3 mentioned: "The main problem now is that my wife is too old to care me thoughtfully and meticulously. Because I am handicapped and it's hard for her to move my body. 
Moreover, my epilepsy will get sick from time to time. When the situation is critical, I still need my children to accompany me to the hospital."

$\bigotimes$ The physical health of the disabled elderly needs a lot of drugs to maintain, but their financial abilities are limited (83/118). As the disabled elderly N117 indicated, "I'm just a farmer and I don't have any income. My sons and daughters-in-law are both disabled currently, they are unable to work and they also have no financial ability to bear my extra expenses."

هBeing with the disabled elderly for a long time, the psychological pressure is heavy(68/118). For example, the son of the disabled elderly N33 said, "As a caregiver, my biggest difficulty is that I am occupied in looking after my disabled parents. Moreover, the emotional status of my parents are unstable, they sometimes act like children. It requires me to be very meticulous, considerate, and obedient them. I often wipe my tears off secretly, and I feel too much pressure to talk about it."

$\bigotimes$ There is a gender gap between the caregiver and the disabled elderly, and the nursing process is embarrassing (e.g. daughter-in-law taking care of father-in-law). (61/118). An elderly female N51 mentioned, "I am getting older and I cannot take care of myself. It is not proper for my son to be

my helping hand, such as bathing, so I have to wait for my daughter when she is free.".

Qlt is difficult to keep the balance of caring for the elderly with their own works and their family lives (53/118). For example, N59's son said, "My wife had a car accident a few years ago, and the steel plate is still in her body. But I also have to work, it is stressful for me to look after my mother and my wife at the same time."

$\nabla$ Lack of professional nursing knowledge (34/118). As the daughter of N96 mentioned, "The elderly often stay in bed for a long time, I have to perform tasks such as 'nasal feeding' and 'sputum suction' for the elderly. It's difficult for me to conduct it, and I don't know how to do."

\There is a controversial issue about the division of responsibilities within the disabled elderly family (12/118). For example, the young daughter-in-law of N107 as the primary caregiver said, "The elderly has 6 children, and I am the daughter-in-law of the youngest son. I have said many times that children should discuss the elderly's care issues together, but there is no way to organize family meetings. Some children rarely pay little money for the elderly, and even some children neither pay nor contribute. I am 53 years old and also have my parents to take care of, but I have spent much time on this part."

2.4 The situation of care services provided by neighborhood committees, volunteers, neighbors, care institutions, etc.

(1) Not provided. $(63 / 118)$

The disabled elderly N19 mentioned, "Currently, the neighborhood committee or other institutions haven't provided any care services for us. Although the neighborhood committee in our village has an old-age care institution, it is only for the uninsured or those who have no children."

The disabled elderly N60 told the researcher, "When I lived in my hometown, my neighbors knew each other, but now I have moved to a new community, no one comes to help me, even greeting. Everyone in the building closes the door and avoids contacting with others."

(2) The neighborhood committee/ brigade have provided assistance (55/118).

Page $10 / 28$ 
The disabled elderly N1 said that "The brigade members of our village will come to my home to deliver some free condolences to me during the Spring Festival or other holidays, and organize people to give us free haircuts every two months."

As the disabled elderly N77 put it," The committee members usually conduct regular health and safety inspections. They will check on my health condition and ask if I need help, and also accompany me to the hospital for medical treatment when I need.";

(3) Neighbors or volunteers have provided assistance (9/118).

The disabled elderly N65 recalled to mind, "Volunteers have come to my home and know some essentials, but they come occasionally and the activities are not permanent. They can't help me if there is an emergency."

2.5 The status of contracted services provided by family doctors for the disabled elderly

The 118 disabled elderly interviewed have their own contracted family doctors from the local community health service center and they all know the doctors' telephone number. Among these participants, only 2 elderly said that they had not received any services from the family doctors, while the 116 disabled elderly were provided different services by their family doctors. It is understood that , the order of service items are as follow: regular telephone follow-up, health knowledge guidance, regular physical examination, changing of urinary catheter and gastric tube at home, injection at home, WeChat/telephone consultation at any time, making appointments or referrals, rehabilitation training, and psychological comfort.

\Regular telephone follow-up (101/118). The disabled elderly N88 mentioned, "The family doctor call me regularly to ask about my health condition and provide me with medication guidance to understand my health better."

QHealth knowledge guidance (98/118). The caregiver (wife) of the disabled elderly N91 mentioned that "Family doctors will come to the village to hold a health lecture and teach us how to take care of the disabled, such as how to prevent bedsores, I think did as what I have learnt that is good for my husband.";

QRegular physical examination (84/118). The disabled elderly N7 mentioned that "Family doctors will provide door-todoor services, such as ECG examination, blood pressure and blood glucose measurement, etc."

\Changing the urinary tube/gastric tube and deliver medicine at home (78/118). As the wife of the disabled elderly N22 mentioned, "Family doctor changing the urinary catheter and gastric tube at home has helped me solve a big problem, because I am too old to take my husband to the hospital regularly."

QInjection at home(69/118).The disabled elderly N8 mentioned, "Now I have to get two injections every week. I can't go to the hospital by my own because of the disability or call an ambulance every time as a result of my poor financial ability, so it is a wise choice that call my family doctor to come and inject at home."

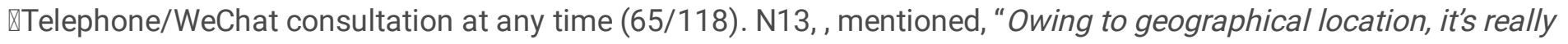
difficult for us who live in the mountainous area to see a doctor. Therefore, many of health problems have been solved through WeChat online."

\Making appointments or referrals (43/118). The disabled elderly N64 referred to, "My family doctor can help me make appointments and register in a large hospital, so that I can go to the superior hospital conveniently"; 
\Rehabilitation training (34/118). The disabled elderly N55 mentioned, "The family doctor has helped me with rehabilitation training, so I am able to walk with the railing now."

खPsychological comfort (33/118). The disabled elderly N83 mentioned, "For those people who are seriously ill, most doctors would pay more attention to their physical health. While my family doctor will chat with me every time, which makes me feel I have a doctor friend."

2.6 The services demands of the disabled elderly and their families for the multiple subjects involved in the process of home care

\subsubsection{Government}

QIncreasing financial support (91/118). The disabled elderly N9 mentioned, "For our peasant family, having a disabled elderly means severe financial pressure. I hope that the government will provide financial assistance for us every month. I think the disability subsidy of 600 RMB is not enough to meet life's basics."The disabled elderly N70 supplemented, "I hope the government will increase the reimbursement limit of medical insurance."

QStrengthening efforts to encourage volunteer service (88/118). The N28 mentioned that “Through our government's publicity on volunteer service, more young people will like to participate in the volunteer activities and help more people like us."

QExpanding the service scope of the elderly care post, increasing the service items, and reducing the charging standard (84/118). The N81 mentioned, "I think the service items of the elderly care post are limited and the disability subsidy can only be used in the post, while I believe the service charges of the post are more expensive than the outside."

هImproving relevant policies, laws and regulations for the elderly (68/118). The N73 noted "For some elderly who have lost quality of life, I strongly believe that the government should introduce the policy of euthanasia."; N92 said, "I hope to accelerate the process of assessing the qualification. At the same time, the subsidy should be made a clearer policy, and establish a mechanism for supervision and feedback."

\Caring more for the elderly (79/118) The N64 mentioned, "I hope the government will take a priority to the elderly and show the equality on this special group, making us feel 'we are the same' "

\subsubsection{Family doctor team}

Enlarging the scope of services and carrying out rehabilitation training at home(94/118). N3 mentioned that "I hope my family doctor can provide rehabilitation training for me at home."

\Conducting regular health education for caregivers (88/118). The N7 noted "I hope that family doctors can popularize hygiene knowledge, supervise family members and give them health guidance"; the N23 referred to, "Family doctor should provide more health guidance and education for the disabled elderly and their counterparts. Professional care knowledge, such as suck sputum, changing the urinary tube/gastric tube, also is essential for the primary caregiver to learn."

QEstablishing family hospital beds (85/118). The N76 mentioned, "I hope to have a hospital bed at home, and doctors visit regularly."

\Calling more often to express concern (71/118). The N6 mentioned, "I hope the family doctor can contact with us frequently and show more care for us, especially for our health"; N11 said, "I hope family doctors focus more on the 
family members of the disabled elderly and help them release their stress."

QEstablishing the "green channel" (71/118). The N67 mentioned, "I think CHS centers should open a "green channel" for the elderly. I queued for a long time when I got a vaccine last time, but my body couldn't bear it."

\subsubsection{Family members}

QProviding financial support (111/118). The N54 mentioned that "children should observe filial piety to share the responsibilities and take care of the elderly';

\Accompanying the elderly more and paying more attention to their psychological problems $(109 / 118)$. As the disabled elderly N72 mentioned, "It is good for my children to keep me company, I need them especially during the Spring Festival."

QLooking after with more patience (87/118). The N87 mentioned that "Family members mainly attend my daily life. So I think that they need to be more careful and patient in the process of home care."

QLearning health care knowledge (73/118). The N53 said, "I hope that my family members take the initiative to attend the health lecture and learn health care knowledge."

\subsubsection{Society}

\Providing voluntary services (106/118). The N77 mentioned, "I wish that social organizations can exert their power and help more people with disabilities, for example, I need volunteers sometimes come to my home and give me a helping hand such as shopping."

\Creating a harmonious social atmosphere and respecting the elderly (88/118). The N67 mentioned that " $A$ harmonious social atmosphere is necessary for the elderly, social group should consider more about the elderly and raise them the social status, which can make us realize the value of ourselves."

\Creating a professional health care service platform of home care(63/118). The N67 mentioned that "Except for the elderly post, there is no formal and professional platform to provide home care assistance for the disabled elderly. However, the fact is that we can't afford the expensive services of the post."N30, said,"Although my nanny does a good job in looking after me, she is less educated and lacks knowledge about nursing."

QThe neighborhood committees spare no effort to help the elderly and their families (56/118). As the disabled elderly N64 mentioned, "Now, the neighborhood committees show little care to the elderly and committees members not carry out their obligations. I hope that committees' members really do some practical work."

『Offering financial support (18/118). The N51 mentioned, "I hope that social groups can give more financial assistance or subsidized items to the disabled elderly, because they are shouldering the heavy burden."

\subsubsection{The elderly themselves}

QIncapable (89/118). Most of the disabled elderly mentioned in the interview that they weren't able to bear health responsibilities anymore, even their consciousness would be blurred from time to time.

QFollowing the doctor's advice(22/118). The N45 mentioned, "The family doctor's advice is beneficial, so I have broken some old habits, such as smoking and drinking and live in a good lifestyle." 
\Controlling the temper(11/118). The N76 said, " I have a bad temper, and I will be angry with some trifles, which has made my health conditions more terrible. Therefore, I have to control my temper now."

Based on the interview results, the researchers have drawn up a schematic diagram which describes the relationships among multiple subjects involved in the service supply process of home care for the disabled elderly, as shown in Figure 1.

\section{Discussion}

3.1 The necessity of multiple subjects participating in home care for the disabled elderly

At present, a global agreement is within reach that population aging has been a tough sell exerting a profound influence on the sound development. China is no exception[6]. Moreover, China's aging population is characterized by aging, empty nesting, high disability rate, and high incidence of chronic diseases. It is more difficult to tackle the problem[7]. Affected by the Chinese traditional culture, the elderly is reluctant to leave their familiar living environment and go to the institutions of health care[8].

On the one hand, with the further increase of disabled elderly, and decrease of family size, the home care provided by children and family members is becoming more and more inadequate[9]. On the other hand, welfare pluralism theory provides a theoretical basis for the multiple subjects to participate in the process of home care. The theory of welfare pluralism notes that through the interaction and coordination among the multiple subjects, care resources can be effectively integrated, so as to maximize welfare[10]. However, the survey results show that family members still play a key role in supporting the disabled elderly in China. The government takes main responsibility for social disadvantaged groups, , family doctors may only play a guiding role, but social organizations play a very little compensation role. In addition, due to the large number of disabled elderly, the large demand and the long duration, care resources provided by a single sector cannot tailor to the needs. Therefore, it is necessary for the government, family members, family doctor team, society and other multiple subjects to participate in the home care system, and form an integration mechanism in which multiple subjects share the responsibility. In a bid to wield the resources from relevant sectors to popularize home care, the cooperation among multiple subjects can complement each other's advantages and provide home care resources more efficiently and accurately.

3.2 Inefficient coordination mechanism among multiple subjects in home care for the disabled elderly

Although the government, family doctors, family members, society, and even the disabled elderly themselves, all perform the different functions of home-based care services for the disabled to varying degrees, the research results show that the coordination mechanism among the subjects has not yet been formed. After extensive review of relevant literature and repeated discussion by panel experts, this study has summarized the functions of multiple subjects in the home care of the disabled elderly, as shown in Table 4 below: 
Table 4 The functions of multiple subjects in home care of the disabled elderly

\begin{tabular}{|c|c|c|c|c|c|c|}
\hline \multirow[t]{3}{*}{ Subject } & \multirow[t]{3}{*}{ Government } & \multirow[t]{3}{*}{ Family Doctor } & \multirow{3}{*}{$\begin{array}{l}\text { Family } \\
\text { Member }\end{array}$} & \multicolumn{2}{|l|}{ Society } & \multirow{3}{*}{$\begin{array}{l}\text { The Disabled } \\
\text { Elderly }\end{array}$} \\
\hline & & & & Non-profit & For-profit & \\
\hline & & & & Organization & Market & \\
\hline Role & $\begin{array}{l}\text { Supplier; } \\
\text { Policymaker; } \\
\text { Supervisor }\end{array}$ & Supplier & $\begin{array}{l}\text { Supplier, } \\
\text { Consumer, } \\
\text { Supervisor }\end{array}$ & $\begin{array}{l}\text { Supplier, } \\
\text { Supervisor }\end{array}$ & Supplier & $\begin{array}{l}\text { Supplier, } \\
\text { Consumer, } \\
\text { Supervisor }\end{array}$ \\
\hline Motivation & $\begin{array}{l}\text { Government } \\
\text { Responsibility, } \\
\text { Public } \\
\text { Interests }\end{array}$ & $\begin{array}{l}\text { Duty, } \\
\text { Responsibility }\end{array}$ & $\begin{array}{l}\text { Responsibility, } \\
\text { Family } \\
\text { Interests }\end{array}$ & $\begin{array}{l}\text { Spontaneity, } \\
\text { Public } \\
\text { Interests }\end{array}$ & Profit & $\begin{array}{l}\text { Independence, } \\
\text { Health Rights }\end{array}$ \\
\hline Aim & $\begin{array}{l}\text { Promote } \\
\text { Health Equity }\end{array}$ & $\begin{array}{l}\text { Protect } \\
\text { Health }\end{array}$ & $\begin{array}{l}\text { Maximize Self- } \\
\text { utility }\end{array}$ & $\begin{array}{l}\text { Maximize } \\
\text { Social } \\
\text { Benefits }\end{array}$ & $\begin{array}{l}\text { Maximize } \\
\text { Benefits }\end{array}$ & $\begin{array}{l}\text { Maximize } \\
\text { Self-Health } \\
\text { Rights }\end{array}$ \\
\hline Mechanism & Bureaucracy & Job duty & $\begin{array}{l}\text { Family Mutual } \\
\text { Aid }\end{array}$ & Voluntary & Market & $\begin{array}{l}\text { Autonomous } \\
\text { Participation }\end{array}$ \\
\hline Advantage & $\begin{array}{l}\text { Authoritative } \\
\text { Guidance }\end{array}$ & $\begin{array}{l}\text { Professional } \\
\text { Assistance }\end{array}$ & $\begin{array}{l}\text { Emotional } \\
\text { Support }\end{array}$ & $\begin{array}{l}\text { Free } \\
\text { Supplement }\end{array}$ & $\begin{array}{l}\text { Diversified } \\
\text { Services }\end{array}$ & $\begin{array}{l}\text { Proactive } \\
\text { Cooperation }\end{array}$ \\
\hline $\begin{array}{l}\text { Dis- } \\
\text { advantage }\end{array}$ & $\begin{array}{l}\text { Government } \\
\text { Dysfunction }\end{array}$ & $\begin{array}{l}\text { Low } \\
\text { Responsibility }\end{array}$ & Weak Support & $\begin{array}{l}\text { Voluntary } \\
\text { Dysfunction }\end{array}$ & $\begin{array}{l}\text { Market } \\
\text { Dysfunction }\end{array}$ & $\begin{array}{l}\text { Capability } \\
\text { Limitations }\end{array}$ \\
\hline
\end{tabular}

\subsubsection{Lack of consistency in the goals of multiple subjects}

The above table shows that each subject has its own focus, and there is a lack of unified consensus about caring for the disabled elderly people. Long-term elderly care services can help meet the greatest needs of the disabled elderly and improve their life quality, which are provided by their family members on the basis of blood relationship and ethics. While family doctors, inspired by their duties and job requirements, provide medical care and medical insurance for all patients within their personal responsibilities[11]. As the final target of the for-profit market is pursuing maximum benefits, quality and types of care services for the disabled elderly can be improved through competition under such circumstances. Until recently, increasing access and well-being for seniors with disabilities has been regarded as one of the government's medium-and long-term plan. However, the harsh terms of assistance and low subsidies are far from meeting the general needs of the disabled elderly[12]. Moreover, the disabled elderly with selfawareness hope to meet their personal needs and maintain their personal health, which reflects the interest appeals for multiple subjects from different sides.

\subsubsection{Low participation and insufficient resources input of multiple subjects}

At present, a multi-subject coordination mechanism involving home-based care for the disabled elderly has initially taken shape, but the existing service forms are merely the accumulation of functions among various subjects. Family members are still the main provider of home care. In addition, the survey results indicate that the insufficient engagement of multiple subjects in home care leads to a low level of services supply and the total resources input cannot meet the demands of the disabled elderly. As a result, families are forced to assume responsibilities that do not accord with their abilities[13].Moreover, it is difficult for the government to consider the needs of each disabled elderly 
due to limited resources and difficulty in equal allocation. Also, the scale and number of staff also hinder family doctors from serving the disabled elderly better. What's more, public welfare social organizations are not engaged in home care at the most time because they do not have sufficient motivation[14], while the limited purchasing power of the disabled elderly in for-profit market leads to a long payback period, which restrict the development of service forms, standards and even the whole industry[11].This indicates that social resources and power have not been fully utilized. Therefore, the above problems reside in the fact that multiple subjects are neither fully involved in home care of the disabled elderly nor motivated properly to provide sufficient resources for those disabled people.

\subsubsection{Lack of coordination among multiple subjects involved in the process of home care}

It is obvious that the actions of multiple subjects involved in the process of home care lack coordination, and the home care resources that government, family doctors, family members, society provided for the disabled elderly don't coordinated [15]. With the increasingly serious aging of Chinese society, the disabled elderly and their families are suffering more from triple stresses of the finance, body and emotion. They are still the primary undertakers of home care. Hence, the government has the responsibility to provide care and assistance through Care Payment or other forms to relieve financial burden of the disabled. Family doctors should play an important role in the health management and medical care for the disabled elderly. Public welfare social organizations take the initiative to provide the voluntary services, and the profitable market triggers a cycle of virtuous competition[16]. In this way, multiple subjects can provide certain supplementary services through their own platforms, thus reducing the burden of the disabled elderly and their families. However, there are differences in the roles and responsibilities among these different subjects, which makes it difficult to coordinate and integrate the resources of each subject, and the quality of home care for the elderly with disabilities is poor.

3.3 The diversified care services supplied by multiple subjects to satisfy various demands of the disabled elderly

\subsubsection{Government guidance}

3.3.1.1 Improve the subsidy policy and guarantee the disabled elderly's legitimate rights and interests

In 2019, the Beijing Municipal Civil Affairs Bureau formulated the policy of "Administrative Measures for the Administration of Subsidies for Elderly Care Services in Beijing", which assesses the eligibility of the disabled elderly who have submitted the application for subsidies. Then, according to the different degree of disability of the elderly, the government will provide nursing subsidies ranging from 200 yuan to 600 yuan to them[17]. However, many disabled elderly families can hardly pay for their expenses. Taking care of the disabled elderly at home makes things worse, and government subsidies are just a drop in the bucket. Most disabled elderly families live in poverty and suffering. Therefore, the government should dynamically adjust the social welfare subsidy policy in combination with the regional economic development level and $\mathrm{CPI}$ rising index, give full play to the functional role of the financial department in social security reform, and steadily improve the social security level of the disabled elderly people[18].

Currently, the subsidy for disabled elderly people is issued by the government to their Incapacitated Security Card, a personal account that can only be consumed at certain service stations such as the elderly-care post, and this kind of allowance is not available for withdrawal. Consumer services provided by the elderly post include: helping the elderly take a bath, cleaning their rooms, and changing the urine pads and so forth. Although the government has made great efforts, the effect of subsidy policy is less than satisfactory. Unreasonable consumption pattern and imperfect service model hinder those elderly from enjoying their legitimate rights, unaffordable price and poor quality of services in senior stations contribute to the unhealthy tendency in Chinese society. Therefore, government departments should improve the social recognition of the subsidies for the disabled elderly, strengthen the dynamic supervision of elderly

Page 16/28 
care stations in society, and evaluate the service qualifications of third-party organizations, especially service price and quality. Moreover, the government should establish a reasonable and effective supervision and feedback mechanism to ensure that the disabled elderly and their families can enjoy services without being restricted by location. [19].

\subsubsection{Enhance the policy publicity and ensure the disabled elderly to enjoy their benefits timely}

One of the criteria for evaluating the effectiveness of government's efforts is the strength of policy publicity. Therefore, the propaganda department should enhance the popularization of the policy, ensure the disabled elderly and their families can know it in time, especially for those living in impoverished areas. Local neighborhood committees should become the bridge for information transmission, connecting the government and the elderly disabled families. Council members in the committee should undertake their responsibilities for its management and policy publicity in local regions. Besides, the Civil Affairs Department should implement relevant public welfare policies and accelerate assessing the qualification of the disabled elderly to ensure that the rights and interests policies for the elderly are fully implemented.

\subsubsection{Promote the development of palliative care and speed up the legislation construction on euthanasia}

Compared with other developed countries, the work of palliative care in China started relatively late. In July 1988, Tianjin Medical College established the first hospice care institution in mainland China, namely "Hospice Care Research Center of Tianjin Medical College". Since then, palliative care institutions have sprung up across the country, but most of them are concentrated in metropolises such as Beijing and Shanghai. Owing to the unreasonable distribution of medical and health resources, it is difficult to meet the general needs of patients for palliative care.

Palliative care includes multi-level service, aiming at alleviating the pain of patients at the end of their days and improve the quality of life[20]. However, influenced by Chinese traditional culture, there is a general dispute about palliative care that whether patients should give up treatment. Ancient Chinese regarded hair as life, just as the saying goes, "Skin and hair are given by the parents, and they dare not hurt them." While palliative care is a treatment to relieve, rather than cure. Restricted by their traditional ideas, the Chinese people ignore the advantages of medical services and the importance of death education [21].

Along with palliative care, China has also proposed the legalization of euthanasia since 1993, but it has not been put into practice so far[22]. The focus of this proposal is to give the suffered a right to choose death with dignity and bring the tortured an end when they can't bear the pain of illness. As there are many diseases that can't be cured by medicine, and there is still a long way to go in medical technology. Those critical patients suffered from both physical and emotional pains, so some of them may choose death with dignity. Therefore, it is urgent for the government to promote the development of palliative care and the legalization of euthanasia, and to ensure that dying patients such as the disabled elderly can make their own choices.

\subsubsection{Family doctor assistance}

\subsubsection{Strengthen contract spirit and implement health management of the disabled elderly}

More than 4,100 teams of family doctor have been established in Beijing. By 2019, 7.4 million people have signed up

with family doctors, with an average of nearly 1,800 people in each team. Among the residents who have signed the contract, the signing rate of key group such as elderly patients with chronic diseases reached over 90 . The National Health Commission made an announcement about family doctor service in 2019, which ask family doctors to "provide door-to-door medical and health services for disabled and semi-disabled elderly, disabled people, terminally ill 
patients and other people who are in urgent need, and extend the contracted services from institutions to communities and families."[23]

Disabled elderly people, as a key group, are in urgent need of family doctor services. The community health service institutions located in Beijing all have all started signing up services for the disabled elderly people. About $4 \%$ to $5 \%$ of the contracted clients of each doctor team are disabled elderly people. In this study, 2 of the 118 disabled elderly people mentioned that they had signed with their family doctors but had never received any services, which indicated the contract between family doctor and the patient is invalid. Low contact frequency and trust may cause a bad contract service relationship. Currently, the effects of family doctor project are not obvious. Therefore, family doctors should deliver health eduction to their disabled clients and make them realize the advantages of having a family doctor. Through long-term health education, family doctor can establish a stable relationship with their clients and the elderly themselves can also enjoy the benefit from such contracted services [24]. At the same time, family doctors should actively connect with their clients, spread their services, increase the frequency of regular home calls, detect the health problems of the disabled elderly [25], and provide health management in time [24]. Only in this way can family doctor team bridge the gap between the doctors and the disabled elderly, and make their contract services more effective.

\subsubsection{Expand the aspects of services to satisfy diversified demands of the disabled elderly}

Unlike healthy elderly, the disabled elderly have greater demands for family doctor services (General Practitioner Services), particularly for family care bed. Currently, the community health service (CHS) centers in Beijing provide limited medical resources for the disabled elderly, and the contract services are poor, which limits the benefit of those in need. For one thing, with limited family beds, it is difficult for those disabled elderly to fully enjoy home-based injections, infusion care and other services; for another, they also face many difficulties when going to the hospital for medical treatment due to their bad physical situations. Consequently, the disabled elderly have great demands for family doctors to bring indoor medical services, such as injection and infusion.

In addition, studies have shown that early intervention of disability has a significant effect on controlling the disease process and improving health condition[18], and the elderly with mild disabilities have a great demand for rehabilitation training in this survey. While, the family doctor team lacks rehabilitation training services at present and the team doesn't have any rehabilitation physiotherapist to meet the diverse needs of the disabled elderly in community.

What's more, staying at home for a long time leads to a sharp decline in social relations of the disabled elderly, and they are grumpy or depressed; their family members also have psychological burden after long-term care [25]. In this study, disabled elderly people often consider that they are worthless and no longer able to contribute to society or even the family. They think that there are many drastic changes in their lives, which will bring great difficulties to their families. Therefore, it's necessary for family doctors to expand contacted services, pay more attention to the mental health of the disabled elderly and their families, and provide them with more medical assistance and psychological counseling, so as to improve the life quality of the disabled elderly.

\subsubsection{Family member guardianship}

"Getting old before getting rich" is the mainstream trend of China's aging society[26]. As a developing country, China cannot totally assume the responsibility of elderly-care. Therefore, home care is still the basic care mode for the elderly[27]. Young people who provide care and support responsibilities for the elderly are still the backbone of elderlycare. 
3.3.3.1 Clarify the division of responsibilities within the disabled elderly's family

The results show that in most disabled elderly families, spouses are the main caregivers, accounting for $35.6 \%$. They gradually replace their offspring to become a major caregiver of the disabled elderly[28], which is consistent with relevant studies. The families interviewed have $2.56 \pm 1.44$ children, which is not affected by China's family planning policy. It can be said that family elderly-care is guaranteed, but the fact is that children in families of the disabled elderly are shouldering less and less responsibility. Generally, those children have their own family life and are busy with work, which makes the sharing of family responsibilities unbalanced, and further causes one of the dilemmas for the disabled elderly[28].

There is a deep-rooted idea of "raising a son as a guarantee against old age" in China, which comes from China's traditional filial piety culture[29]. Most elderly people with son and daughter said in the survey that they would choose to live with their son. A common phenomenon is that children take care of their disabled parents in turns. When the core value of filial piety culture returns back to kinship, it weakens the binding force of children's support for their parents[30]. As a result, in some families, children have great disputes over pension and daily care for their parents, and even shirk their responsibilities.

Therefore, when it comes to supporting parents, the offspring in multiple-child families should be fair and just, and distribute responsibilities according to income and residence distance to the elderly, particularly in the distribution of pension and medical expenses[28]. These measures can prevent children from disharmony, and protect one person from undertaking too much pressure on himself/herself due to improper arrangements. What's more, the eldest son or daughter should play a leading role, coordinate family relationship, strive to create a positive family atmosphere and make sure the disabled elderly live in harmony.

\subsubsection{Provide financial support, high-quality care and company}

Family care usually includes three aspects: material support, daily care, and spiritual comfort. Family members, as the guardian of the disabled elderly, are the first to bear the disabled elderly's healthcare expenditure. They should provide financial support to meet the material needs of the disabled elderly, and protect health benefits for the elderly by purchasing movable beds, installing anti-slip rails, and other equipment suitable for them[19].

Family caregivers play an important role in the home care for the disabled elderly, and their knowledge affect the quality of home care[31]. As primary caregivers, family members should take initiative to learn health knowledge and actively participate in the care training organized by the contracted family doctor, so as to provide high-quality care for the disabled elderly in home. At the same time, they should keep in touch with the doctor to exchange the health condition of the elderly and ensure timely medical treatment if the elderly get sick.

In addition, there are many traditional festivals in China that symbolize family reunion, such as the Spring Festival, Mid-Autumn Festival and Double Ninth Festival[32]. The Chinese people pay more attention to the family reunion, and the long days of vacation give people a chance to stay with family. In this study, the disabled elderly have extremely high expectations for companionship, as 109 out of the 118 interviewees expressed that they wished to live with their families during traditional festivals. But the fact is that many children have little time to accompany the disabled elderly, except the family caregiver. Therefore, family members should actively coordinate their personal time, pay attention to create a good family atmosphere in traditional festivals, and provide care and companionship to the disabled elderly. In daily life, they should also focus on the psychological problems of the elderly and give timely assistance to reduce geriatric depression[33]. 


\subsubsection{Create a good social atmosphere to respect and care for the elderly}

The current society has some uncivilized concepts and behaviors in the treatment of vulnerable groups such as the disabled elderly, which require great efforts to change. Related studies have shown that social support can relieve loneliness and depression.[34]. Surveys show that one of the obvious psychological problems of the disabled elderly is that they consider themselves a drag on their families, a burden on society, and deny their value in life. When they feel the discrimination from others, they are more worried about their old-age life. Therefore, it is necessary to enhance the cultivation of personal morality and social support, care for the physical and mental health of the elderly, improve the civilization of the whole society, and guide the people to practice the core socialist values.[14].

\subsubsection{Promote voluntary and build a community service system}

Facing the dual dilemma of insufficient care services provided by home caregivers and the government, community voluntary become a supplemental resource [34]. The survey results show that Beijing has not yet formed a systematic volunteer service system for the disabled elderly groups, who are in urgent need of services including accompanying the elderly to the local hospital, providing temporary care at home, purchasing daily necessities, etc. Therefore, community volunteers have great potential to ease the pressure on home care services.

First, long-term and stable interpersonal relationships make it easier for the disabled elderly and their families to release pressure and seek solace from the volunteers $[35,36]$. In this study, most disabled elderly and their families hope to have a volunteer to help them. While the current volunteer activities in Beijing are carried out by some government institutions or staff, unable to provide sufficient funds and long-term voluntary service.

According to relevant studies, community activities, group participation, and friendship networks are beneficial to the elderly's health condition[35]. Therefore, it is recommended that neighborhood committees and other social institutions actively mobilize party members or other volunteers in the community to establish a one-on-one assistance mechanism with the disabled elderly, so as to provide psychological care and support, and assist disabled elderly people to receive medications from hospitals and accompany them to receive medical treatment or other services.

Second, volunteers should receive systematic and standardized training on healthcare knowledge, and the neighborhood committees should accurately match the volunteers to the disabled elderly. Volunteers who have received training can help family caregivers to make simple and correct emergency treatments when facing with sudden health troubles of the disabled elderly, so as to protect their life[13].

Third, establish an incentive mechanism for volunteers. "Time Bank" or "Public Welfare Bank" may become an effective method to improve motivation. That means, every registered volunteer and their service time, types will be recorded in the digital file. Volunteers get credit when they help the disabled elderly, from home care to medical care. These credits can be saved in the "Time Bank" and spent when volunteers are in need. The elderly can also participate in volunteer activities. Research shows that the disabled may be a very important contributor of volunteer organizations, especially middle-aged and those with the potential to generate capital in social networks[36]. Such schemes can encourage volunteers to help the disabled elderly, make their services credit a heritage that can be passed to next generation. In addition, it can ensure sustainable voluntary services, give full play to the functions in social support and cultivate a good social atmosphere of mutual help.

\subsubsection{Improve market environment of home care and attract more enterprises to invest the elderly market}

There are still many thorny problems in the service market of the disabled elderly. The families interviewed in this research have mentioned that they found it's difficult to obtain reassuring services in the market when they need to hire 
nannies or enjoy other care services.

In 2016, in order to further stimulate market vitality and encourage social capital to enter this industry, the General Office of the State Council promulgated the "Several Opinions on Fully Liberating the Elderly Care Service Market and Improving the Quality of Elderly Care Services", which provided loans for relaxing the access conditions of the senior care service industry. In 2019, the General Office put forward the "Opinions on Promoting the Development of Elderly Care Services", in order to remove the obstacles to the development of the elderly care services industry, and carried out all-round work arrangements to eliminate obstacles to the elderly care services industry. However, the current market development of the home care services industry for the disabled is still sluggish.

Therefore, society should promote the concept of respecting and loving the elderly, attracting more enterprises to invest in elderly care services market, establish a comprehensive regulatory system to encourage benign competition and improve market climate of home care services. In this way, on the one hand, it can meet the demands of the disabled elderly and their families, thus liberating family labor[37]; on the other hand, a competitive care services market will help companies keep improving and provide better services in home care[38].

\subsubsection{The disabled elderly cooperation}

Traditional health theory suggests that when health hazards are related to the individual lifestyles and behaviors, and medicine don't work, then the individual's control of their own behavior will become an important way to promote health[39].In other words, when individual chooses an active and healthy lifestyle, they tend to have better health conditions and pay less on medical services. For example, abandoning unhealthy behaviors such as smoking and alcohol abuse would keep patients away from diseases. At the same time, related research shows that there are two arguments supporting the elderly to be responsible for their own health: one is for their own interests and the other is relief on social pressure[40]. That means, first, the elderly should protect their own health; second, they should reduce the medical burden of the society.

In terms of health, personal responsibility means reducing health risk factors to the extent that the individual can reasonably control them, and the fulfillment of personal health responsibility is mainly manifested in the management of one's own health and self-education[42], but there are limitations in personal health management for the elderly with disabilities. The survey demonstrates that most of the disabled elderly, especially these people who are in the bad situations, have lost the ability to manage their own health. They are bedridden for a long time, unable to defecate or eat on their own, and some of them even have lost their consciousness. Therefore, it is difficult for the disabled elderly group to become the first person responsible for their personal health, and it is impossible to be too strict with them. Other subjects involved in home care cannot rely too much on the disabled elderly's self-care, whereby "self-care" is potentially unachievable and becomes care left undone. This will create a culture of blame for self-care, attributing the elderly's poor health to their personal behavior[41]. This is obviously unreasonable for the disabled elderly to become the first person responsible for health. When the disabled elderly are still partially capable of acting, they should take initiative to protect personal health; when they are still conscious, they can actively adjust their personal emotions, seek assistance from others in time, and maintain their own mental health.

3.4 Advice on improving the coordination mechanism of multiple subjects involved in home care for the disabled elderly

After extensive review of relevant literature and discussion by panel experts, this study summarized a collaborative framework of multiple subjects involved in home care of the disabled elderly, as illustrated in Figure 2. From this pentagonal cooperation mechanism, we can see each subject has a close contact with others. The government

Page $21 / 28$ 
formulates welfare policies for disabled elderly and their families, as well as incentive policies for family doctors to encourage them to help the disabled elderly, and gives policy guidance to social organizations. Other subjects in this cooperation mechanism give feedback to the government at the same time. Family doctors provide medical services for the disabled elderly, give professional technical guidance for the family members of the disabled elderly and they can also join the social organizations as volunteers, which is a useful supplement to keep this mechanism work effectively. Family members of the disabled elderly provide daily care for the disabled elderly, connect family doctor to report the health conditions of the disabled elderly and sometimes ask social organizations for help. Society plays a supporting role in providing help to family doctors, disabled elderly and their families. Therefore, in order to establish a multi-subject pentagonal cooperation mechanism for the disabled elderly people in Beijing, the following suggestions are presented.

\subsubsection{Strengthen the integration of internal resources within multiple subjects}

Institutional structure, information asymmetry or other reasons lead to the mismatching of internal care resources and inefficient services. Therefore, there is an urgent need for concerning subjects to integrate their internal resources from different aspects.

Currently, policies related to elderly care are fragmented and implemented by different government departments. For example, the civil department is only in charge of care subsidies for the disabled elderly, and the medical security department only is responsible for the medical insurance reimbursement ratio. Under such management system, government has lower efficiency in resources distribution and there is a great gap between services provision and the demands of the disabled elderly. This results in the elderly with disabilities being an indivisible individual, but their demands are scattered. Because a clear policy and action plan can help reduce inefficiency and divide in the health care system. Therefore, the government should promote coordination and information exchange among departments[42] and establish a better management system to realize resources integration.

To integrate family doctor team resources, we should flexibly and dynamically adjust the composition of service personnel, and provide tailor-made services to the disabled elderly and their families to meet the diverse needs of the disabled people. [44].

To integrate idle human resources and finance is the main problem faced by family members. It is necessary for families to allocate human resources and financial resources reasonably, so that the disabled elderly can obtain the best home care service at the lowest cost[42].

Social resources integration requires information technology to sort out and match the demands of the disabled elderly and the care services they need.

3.4.2 Define the position of the responsibilities for the disabled elderly and promote the resources integration among multiple subjects

Responsibilities allocation and information sharing are prerequisite for multiple subjects to cooperate with each other and provide services for the disabled elderly in the process of home care.

First, the family and the disabled elderly themselves have a fundamental responsibility for the home care services[43].Traditionally, the individual are mainly responsible for their own health, and family members are the most natural and stable caregivers. However, there are many factors that affect the quality of home care for the disabled elderly, such as the change of family size, the duration of care extend, etc. These all increase the cost and difficulty of home-based care for disabled elderly. [44]. To maintain the basic roles of the family, the government should provide 
economic subsidies and policy support, and family doctors should offer technical guidance and health education to improve family members' care. Social welfare organizations should reduce the pressure on those caregivers through sufficient assistance. At the same time, paid alternative care services should also be developed, so that families can have temporary rest by purchasing alternative services.

Second, the government is the last line of defense for home care security system. Therefore, government should introduce a series of measures to strengthen assistance for those vulnerable disabled elderly, pay more attention to solve the problems brought out by the elderly and their families and make sure enough living and medical resources are accessible to everyone. Encouraging family doctors and social groups to participate in elderly care services for the disabled is also an important step of the government. This point will be explained in detail as the following incentive policies for multiple subjects.

Third, the functions of family physician teams and other social groups are complementary[16]. Family doctor is a useful supplement to home care services, and through contracting services and health management, they can effectively extend the life span of the disabled elderly and improve their quality of life. Public welfare social organizations can bridge the gap when other subjects are unable to provide care services, and they will provide social support for the disabled elderly, and build a good mutual assistance system. Through competition, the for-profit market also can provide affordable and high-quality services for disabled elderly people.

\subsubsection{Incentive policies for multiple subjects involved in home care services for the disabled elderly}

In order to promote the collaboration of multiple subjects, it is necessary to establish incentive policies for them to take initiative to provide home care services. the government should plays its responsibilities in the care of the disabled elderly as they are vulnerable group. It is an important responsibility of the government to mobilize the active participation of multiple subjects[11]. For example, the government can give some subsidies or even weekly vacations to the caregivers in the families of the elderly with disabilities. In addition, targeted funding can be set up in the family doctor team to encourage doctors to provide high-quality care services to the elderly with disabilities. Moreover, the government can promote non-profit social welfare organizations to expand their social benefits and support the forprofit market with public facilities and uniform staff training.

\section{Conclusion}

Homecare for the disabled elderly is becoming more intertwined with society. The demands of the disabled elderly are becoming increasingly diversified, and multiple subjects' participation in the process of home care is becoming more and more important. However, there is currently insufficient home care provided by multiple subjects, and there is a lack of a coordinated mechanism for multiple entities to support the disabled elderly. Therefore, multiple subjects in Beijing should integrate care resources to provide care services for the disabled elderly more efficiently and precisely (e.g., the government should increase the inclination of relevant elderly care policies and strengthen publicity and guidance; family doctors should improve service quality; citizens should create a good atmosphere for the elderly; diversified participation in the service industry for the disabled elderly, etc.) and thus improve the quality of life of the disabled elderly and enhance their sense of well-being . Eventually, the ideal goal of making every elderly with disabilities have a sense of security, support and happiness will be realized in the near future.

\section{Declarations}

Ethics declarations 
All included participants gave their oral and written informed consent and all experiments were performed in accordance with relevant guidelines and regulations. The study was approved by Medical Ethics Committee of Capital Medical University, Beijing, China. (Reference number Z2021SY027).

Consent for Publication

Not applicable.

Availability of Data and Materials

Transcripts will not be shared for online access to protect the anonymity of the participants. Readers who wish to gain access to the data can write to the corresponding author.

Competing Interests

The authors declare that they have no competing interest.

Funding

This study was funded by Beijing Social Science Foundation Project (Funding Number 19JDSRB008). The funding organization had no further role in the study design, data collection and analysis, interpretation of the data, writing the paper and the decision to submit the paper for publication.

Acknowledgements

The author would like to thank the disabled elderly families who participated in this study and completed the interviews and the questionnaires. Through this project, we got to know 118 families of disabled elderly people, and had a long-term friendship with them.

Authors' Contributions

ZR, ZZ, and PY contributed to the conception and design of the research; ZR, ZZ, ZS, ZJ,CJ and PY collection and analyzed the data; ZR, ZZ and PY drafted the manuscript; and other authors revised it. All authors read and approved the final manuscript. All authors agreed to be accountable for all aspects of the work.

Author details

${ }^{1}$ School of Medical Humanities, Capital Medical University, NO 10, Xitoutiao, You An Men Wai , Beijing 100069,China

2 Fengtai District Xiluoyuan Community Health Service Center, Beijing, China

${ }^{3}$ Huairou District Liulimiao Community Health Service Center, Beijing, China

\section{References}

1. Beijing Municipal Bureau Of Statistics BSNC: Beijing Seventh National Census Communiqué ([1])(No. 1). In Beijing Daily:; 2021. 
2. Chang S, Yang W, Deguchi H: Care providers, access to care, and the Long-term Care Nursing Insurance in China: An agent-based simulation. Social science \& medicine (1982) 2020, 244:112667.

https://doi.org/10.1016/j.socscimed.2019.112667.

3. Beijing Municipal Bureau of Statistics:Beijing Health Statistics Yearbook,2020.

4. Kallio H, Pietilä A, Johnson M, Kangasniemi M: Systematic methodological review: developing a framework for a qualitative semi-structured interview guide. J ADV NURS 2016, 72(12):2954-2965.

https://doi.org/10.1111/jan.13031.

5. Kiger ME, Varpio L: Thematic analysis of qualitative data: AMEE Guide No. 131. MED TEACH 2020, 42(8):846854. https://doi.org/10.1080/0142159X.2020.1755030.

6. Jiang H, Liu L, Liu T, Zhu S, Hou L: Current status on the ability of the elderly in rural China: implications for future nursing and policy. Cardiovascular Diagnosis and Therapy 2020, 10(5):1216-1225. https://doi.org/10.21037/cdt20-555.

7. Wu C, Smit E, Xue Q, Odden MC: Prevalence and Correlates of Frailty Among Community-Dwelling Chinese Older Adults: The China Health and Retirement Longitudinal Study. The journals of gerontology. Series A, Biological sciences and medical sciences 2017, 73(1):102-108. https://doi.org/10.1093/gerona/glx098.

8. Shao R, Hu T, Zhong Y, Li X, Gao Y, Wang Y, Yin W: Socio-demographic factors, dental status and health-related behaviors associated with geriatric oral health-related quality of life in Southwestern China. HEALTH QUAL LIFE OUT 2018, 16(1):98. https://doi.org/10.1186/s12955-018-0925-8.

9. Zeng Y, Hesketh T: The effects of China's universal two-child policy. The Lancet 2016, 388(10054):1930-1938. https://doi.org/10.1016/S0140-6736(16)31405-2.

10. Johnson N: Mixed economies of welfare: a comparative perspective: Mixed economies of welfare: a comparative perspective; 1999.

11. Long-Term Care: Efforts Supported By Foundations. Health affairs (Project Hope) 2018, 37(4):674-675. https://doi.org/10.1377/hlthaff.2018.0213.

12. Intrevado P, Verter V, Tremblay L: Patient-centric design of long-term care networks. HEALTH CARE MANAG SC 2019, 22(2):376-390. https://doi.org/10.1007/s10729-018-9445-7.

13. Jiang S, Li C, Wang Z, Fang X: The mediating effect of neighbor relationship between community social support and elderly's subjective well-being in China. J HEALTH PSYCHOL 2020, 25(6):780-790.

https://doi.org/10.1177/1359105317733535.

14. Silva Júnior EGD, Eulálio MDC, Souto RQ, Santos KDL, Melo RLPD, Lacerda AR: The capacity for resilience and social support in the urban elderly. CIENC SAUDE COLETIVA 2019, 24(1):7-16. https://doi.org/10.1590/141381232018241.32722016.

15. Johnson S, Bacsu J, Abeykoon H, Mclntosh T, Jeffery B, Novik N: No Place Like Home: A Systematic Review of Home Care for Older Adults in Canada. Canadian journal on aging = La revue canadienne du vieillissement 2018, 37(4):400-419. https://doi.org/10.1017/S0714980818000375.

16. Van Houtven $\mathrm{CH}$, Konetzka RT, Taggert E, Coe NB: Informal And Formal Home Care For Older Adults With Disabilities Increased, 2004-16. Health affairs (Project Hope) 2020, 39(8):1297-1301.

https://doi.org/10.1377/hlthaff.2019.01800.

17. Beijing Civil Affairs Bureau: Implementation Measures of Beijing Municipality for the Administration of Pension Service Subsidies for the Elderly 2019.

http://www.beijing.gov.cn/zhengce/zhengcefagui/201910/t20191028_454233.html 
18. Read S, Heslop P, Turner S, Mason-Angelow V, Tilbury N, Miles C, Hatton C: Disabled people's experiences of accessing reasonable adjustments in hospitals: a qualitative study. BMC HEALTH SERV RES 2018, 18(1). https://doi.org/10.1186/s12913-018-3757-7.

19. Døhl $\varnothing$, Garåsen $\mathrm{H}$, Kalseth J, Magnussen J: Factors associated with the amount of public home care received by elderly and intellectually disabled individuals in a large Norwegian municipality. HEALTH SOC CARE COMM 2016, 24(3):297-308. https://doi.org/10.1111/hsc.12209.

20. Angell M: Euthanasia.|.*319*319.; 1988:1348-1350.

21. Pu SD: Euthanasia in China: a report. The Journal of medicine and philosophy 1991, 16(2):131-138.

22. Tomlinson R: China considers voluntary euthanasia.|.*310*310.; 1995:761.

23. General Office of the National Health Commission: Notice on Doing a Good Job in Contracting Service of Family Doctors in 2019,2019. http://www.gov.cn/xinwen/2019-04/26/content_5386470.htm

24. Chaix B, Veugelers PJ, Boëlle $P$, Chauvin $P$ : Access to general practitioner services: the disabled elderly lag behind in underserved areas. EUR J PUBLIC HEALTH 2005, 15(3):282-287.

25. Silliman RA: Caring for the frail older patient: the doctor-patient-family caregiver relationship. J GEN INTERN MED 1989, 4(3):237-241.

26. Wang M, Huang Y: Evaluating family function in caring for a geriatric group: Family APGAR applied for older adults by home care nurses.|.*16*16.; 2016:716-721.

27. Kemper P: The use of formal and informal home care by the disabled elderly. HEALTH SERV RES 1992 , 27(4):421-451.

28. Liu X, Lu B, Feng Z: Intergenerational transfers and informal care for disabled elderly persons in China: evidence from CHARLS. HEALTH SOC CARE COMM 2017, 25(4):1364-1374. https://doi.org/10.1111/hsc.12441.

29. Ho DYF, Xie W, Liang X, Zeng L: Filial piety and traditional Chinese values: A study of high and mass cultures. PSYCH J 2012, 1(1):40-55. https://doi.org/10.1002/pchj.6.

30. Bedford O, Yeh K: The History and the Future of the Psychology of Filial Piety: Chinese Norms to Contextualized Personality Construct. FRONT PSYCHOL 2019, 10:100. https://doi.org/10.3389/fpsyg.2019.00100.

31. Lopez NM, Ponce S, Piccinini D, Perez E, Roberti M: From Hospital to Home Care: Creating a Domotic Environment for Elderly and Disabled People. IEEE PULSE 2016, 7(3):38-41. https://doi.org/10.1109/MPUL.2016.2539105.

32. Laidlaw K, Wang D, Coelho C, Power M: Attitudes to ageing and expectations for filial piety across Chinese and British cultures: a pilot exploratory evaluation.|.*14*14.; 2010:283-292.

33. Della Vecchia C, Préau M, Carpentier C, Viprey M, Haesebaert J, Termoz A, Dima AL, Schott A: Illness beliefs and emotional responses in mildly disabled stroke survivors: A qualitative study. PLOS ONE 2019, 14(10):e223681. https://doi.org/10.1371/journal.pone.0223681.

34. Liu L, Gou Z, Zuo J: Social support mediates loneliness and depression in elderly people. J HEALTH PSYCHOL 2016, 21(5):750-758. https://doi.org/10.1177/1359105314536941.

35. Kim D, Kawachi I: A multilevel analysis of key forms of community- and individual-level social capital as predictors of self-rated health in the United States. Journal of urban health: bulletin of the New York Academy of Medicine 2006, 83(5):813-826.

36. Collom E: Engagement of the elderly in time banking: the potential for social capital generation in an aging society. J AGING SOC POLICY 2008, 20(4):414-436. https://doi.org/10.1080/08959420802186282.

37. McDonald T, Russell F: Long-Term Care Quality-of-Life Scale utility in community home care. NURS HEALTH SCI 2019, 21(4):494-500. https://doi.org/10.1111/nhs.12628.

38. Ikegami N: Financing Long-term Care: Lessons From Japan.|.*8*8.; 2019:462-466. 
39. Friesen P: Personal responsibility within health policy: unethical and ineffective. J MED ETHICS 2018, 44(1):5358. https://doi.org/10.1136/medethics-2016-103478.

40. Abbasi M, Majdzadeh R, Zali A, Karimi A, Akrami F: The evolution of public health ethics frameworks: systematic review of moral values and norms in public health policy. Medicine, health care, and philosophy 2018, 21(3):387402. https:// doi.org/10.1007/s11019-017-9813-y.

41. Greaney A, Flaherty S: Self-care as care left undone? The ethics of the self-care agenda in contemporary healthcare policy. Nursing philosophy: an international journal for healthcare professionals 2020, 21(1):e12291. https://doi.org/10.1111/nup.12291.

42. Scheepmans K, Milisen K, Vanbrabant K, Paquay L, Van Gansbeke H, Dierckx de Casterlé B: Factors associated with use of restraints on older adults with home care: A secondary analysis of a cross-sectional survey study. INT J NURS STUD 2019, 89:39-45. https://doi.org/10.1016/j.ijnurstu.2018.07.019.

43. Compton RM, Olirus Owilli A, Caine V, Berendonk C, Jouan-Tapp D, Sommerfeldt S, McPhee DJ, Walz D: Home First: Exploring the Impact of Community-based Home Care for Older Adults and Their Family Caregivers.

Canadian journal on aging = La revue canadienne du vieillissement 2020, 39(3):432-442.

https://doi.org/10.1017/S0714980819000461.

44. Johnson RW, Wang CX: The Financial Burden Of Paid Home Care On Older Adults: Oldest And Sickest Are Least Likely To Have Enough Income. Health affairs (Project Hope) 2019, 38(6):994-1002. https://doi.org/10.1377/hlthaff.2019.00025.

\section{Figures}

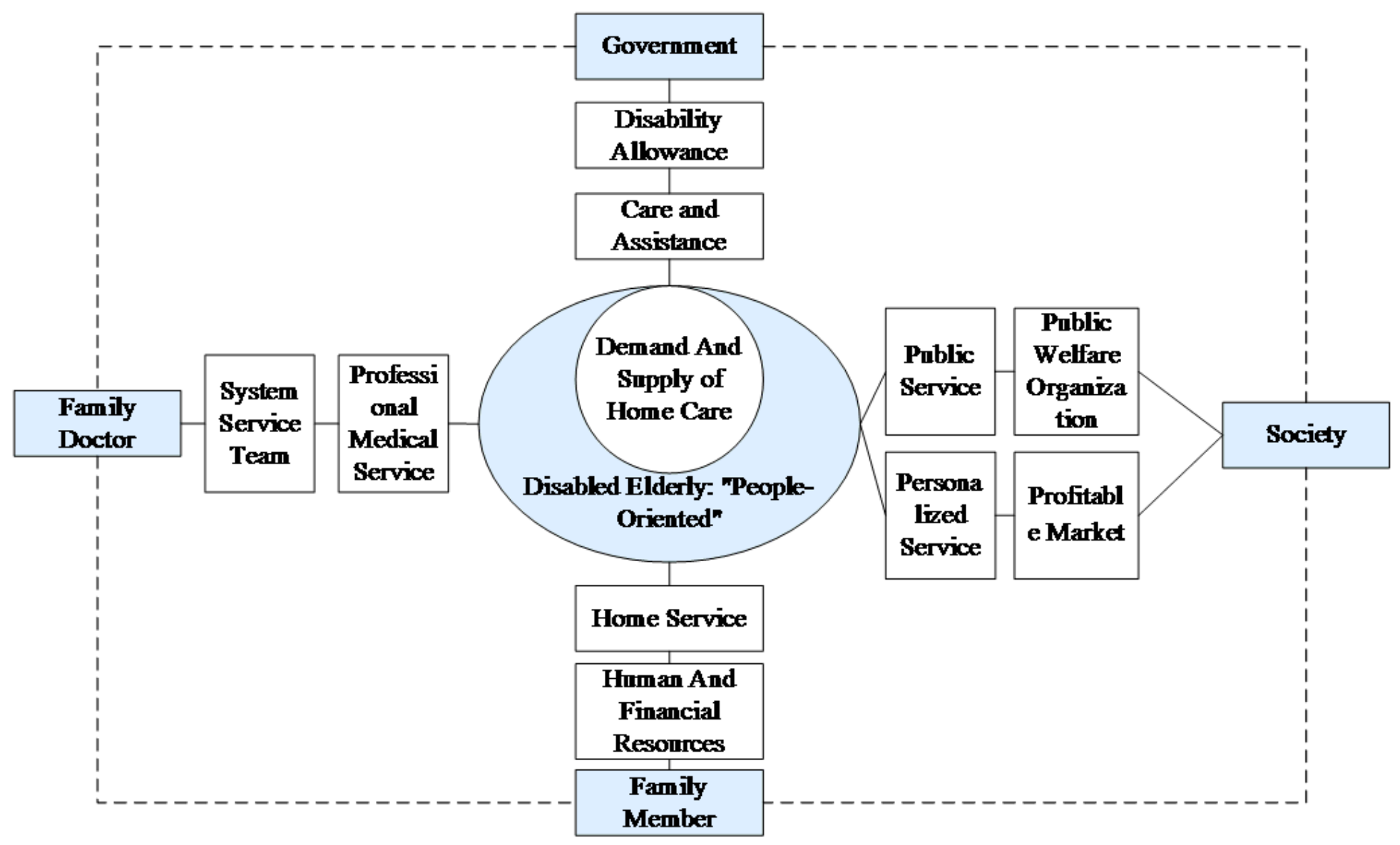

Figure 1 
Schematic diagram of the relationships among multiple subjects involved in the service supply process of home care for the disabled elderly

Note $^{\mathrm{a}}$ : The dotted line represents that the subjects have not yet formed a close cooperative relationship

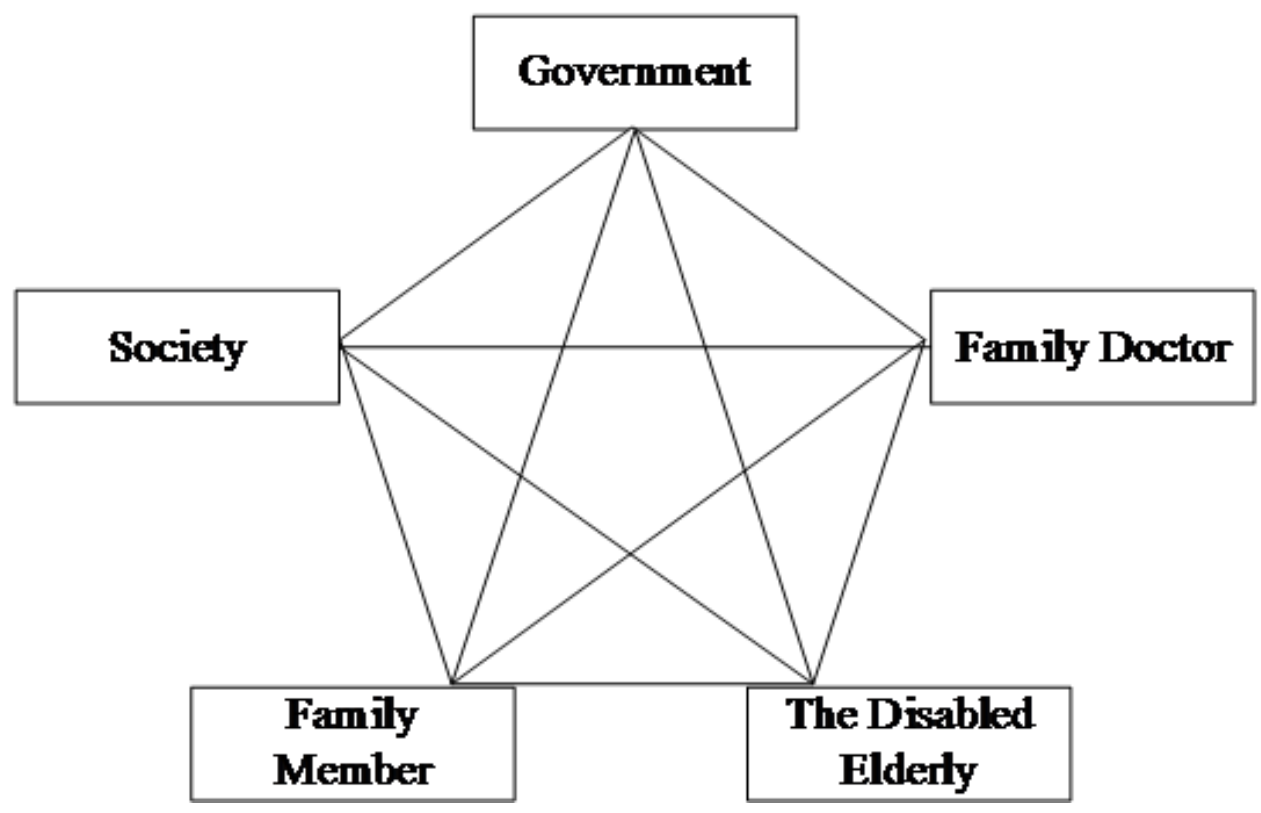

\section{Figure 2}

A collaborative framework of multiple subjects involved in home care for the disabled elderly

Note ${ }^{b}$ : The solid line represents that the multiple subjects have cooperative relationships 